\title{
Defining and Assessing Adverse Environmental Impact: A Collection of Peer-Reviewed Papers
}

\author{
Anne Vindenes Allen \\ TheScientificWorld U.K. \\ Received January 8, 2002; Accepted January 10, 2002; Published January 31, 2002
}

KEY WORDS: environmental assessment, EIA, cooling water, aquatic community and function, power plants, fisheries management, Clean Water Act, regulatory management, ecological risk assessment

DOMAINS: environmental management and policy, freshwater systems, waste management policy, ecosystems and communities, environmental technology

TheScientificWorldJOURNAL is pleased to announce the forthcoming publication of 'Defining and Assessing Adverse Environmental Impact', a collection of peer-reviewed papers from the Symposium of the same name held in association with the $131^{\text {st }}$ Annual American Fisheries Society (AFS) Meeting August 19-23, 2001. Organizer of the Symposium was Douglas A. Dixon, Ph.D., Manager, Fish Protection Research at Electric Power Research Institute (EPRI), assisted by committee members John Veil of the Argonne National Laboratory, James R. Wright, Jr., Ph.D., of the Tennessee Valley Authority, and William Richkus, Ph.D., of Versar, Inc. The Symposium was sponsored by the Electric Power Research Institute.

The Collection presents papers on issues relating to the assessment of impacts of cooling water intake structures (CWIS) to the environment and evaluation of when they are adverse. Because CWIS are located in all water body types, issues relevant to aquatic organisms in streams, rivers (non-tidal and tidal), lakes, reservoirs, estuaries, and coastal oceans are discussed. Specific topics addressed include:

- Definition of AEI (including consideration of the full range of options suggested to date, such as individual losses, population-level impacts, fishery opportunity foregone, disruption of aquatic community structure and function)

- AEI assessment endpoints and thresholds

- Predictive and retrospective methods for assessing AEI (e.g., conditional mortality, equivalent adult losses, production foregone, biocriteria, trend analysis of fisheryindependent, and dependent data)

- Role of ecological risk assessment in assessing AEI

Guest Editors for the Collection are Doug Dixon, John Veil, and Joe Wisniewski. Papers are published as they are accepted, and the final papers are expected published by the end of March 
2002. The Collection will be published in TheScientificWorldJOURNAL Volume 2, 2002 as well as in a printed book version. For further information regarding the online or print version, please contact the publisher at editor@thescientificworld.com.

This article should be referenced as follows:

Allen, A. (2002) Defining and assessing adverse environmental impact: a collection of peer-reviewed papers. TheScientificWorldJOURNAL 2, 268-269. 


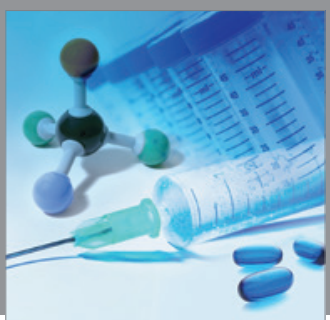

International Journal of

Medicinal Chemistry

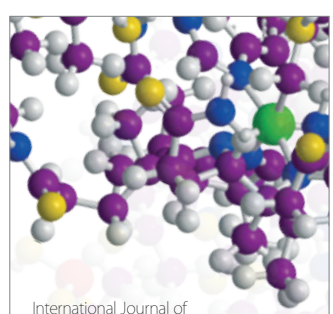

Carbohydrate Chemistry

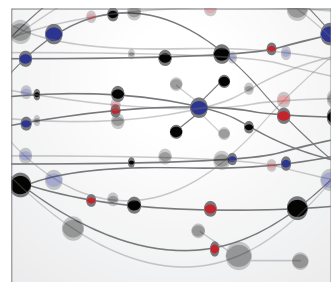

The Scientific World Journal
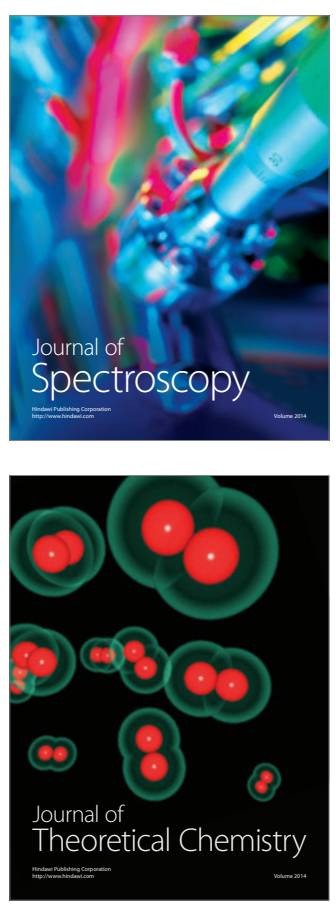
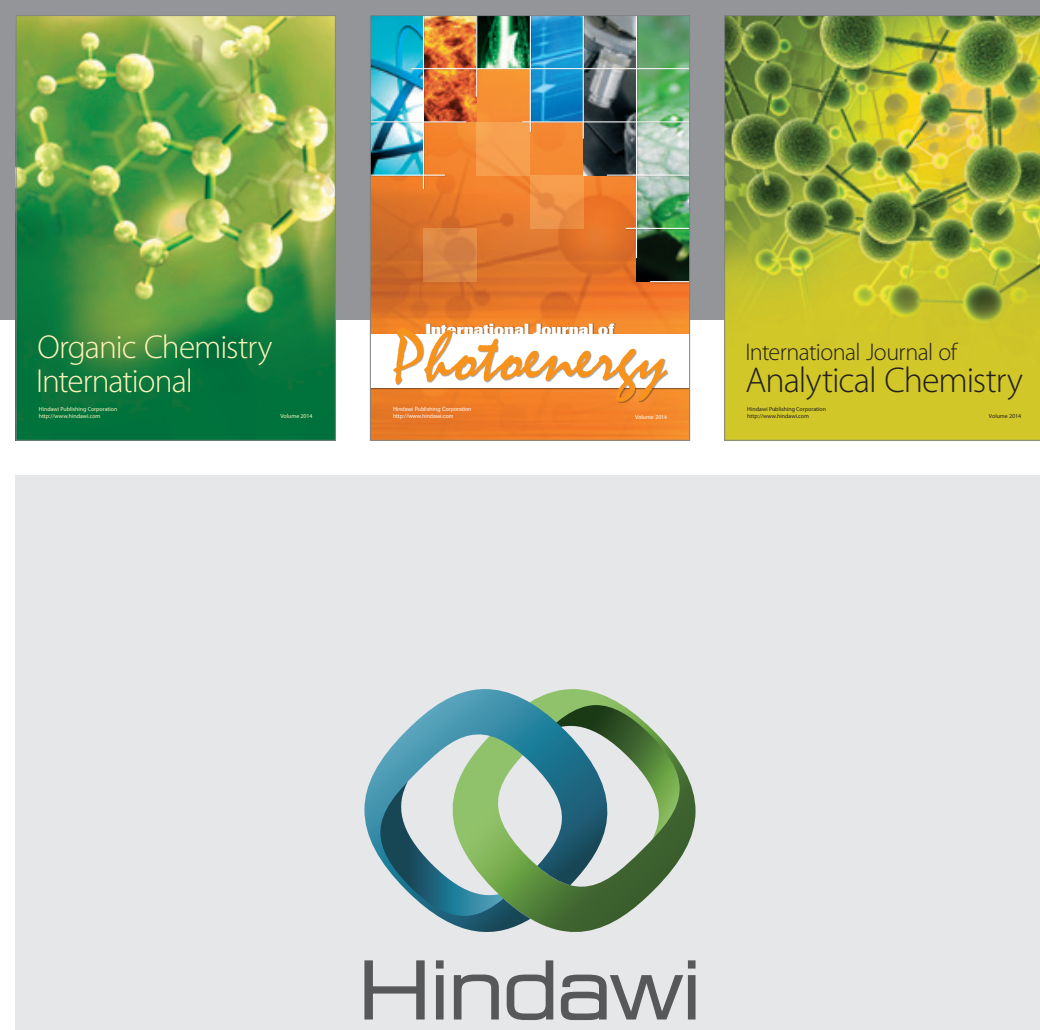

Submit your manuscripts at

http://www.hindawi.com
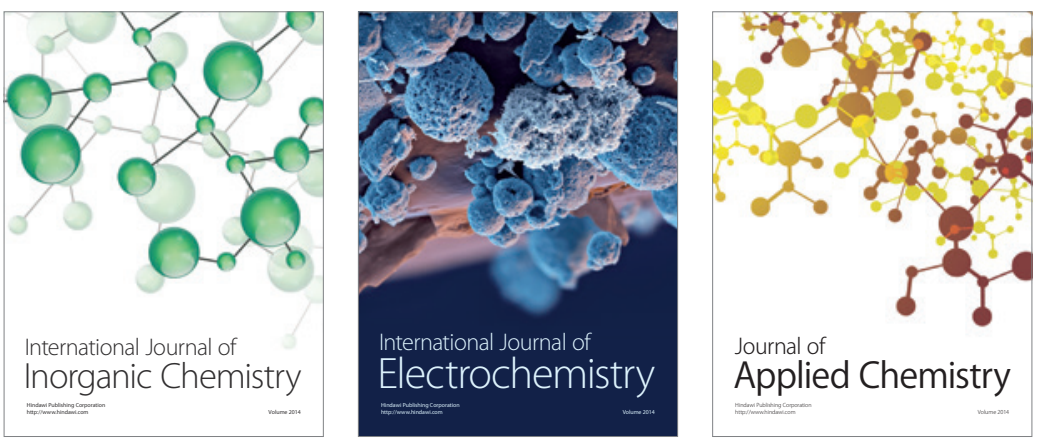

Journal of

Applied Chemistry
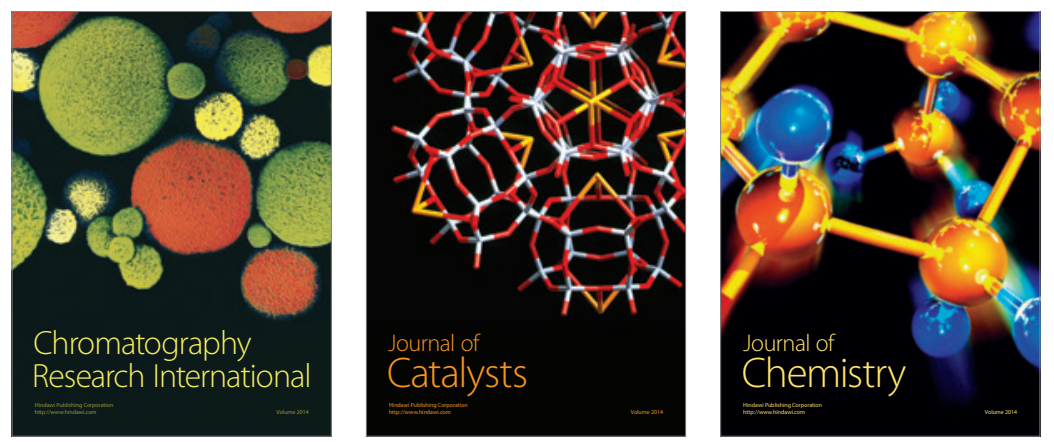
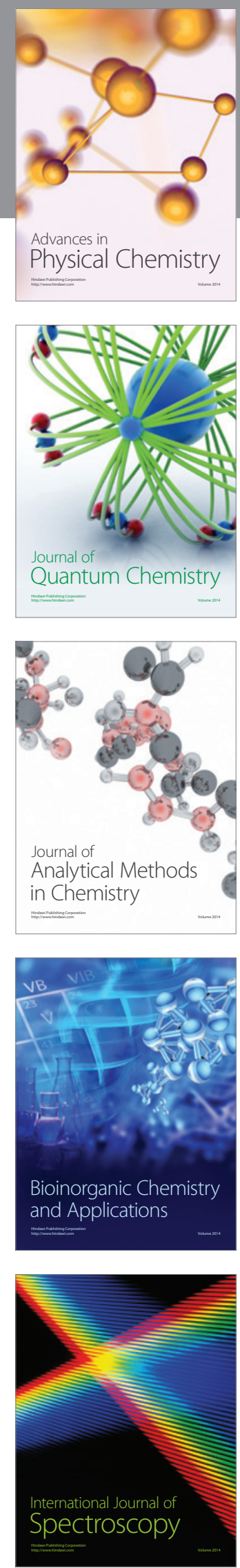